\title{
Die Apostelkonvent - Lukas en Paulus. 'n Vergelykende studie
}

\author{
G M M PELSER
}

Die vraag na die historiese korrektheid van die boek Handelinge se weergawe van die vroeë geskiedenis van die kerk is nie maklik te beantwoord nie. Daar is eenvoudig nie genoeg eksterne gegewens om die outeur se feite te kontroleer nie. Selfs waar met redelike sekerheid vasgestel kan word dat die outeur eiehandig geformuleer het $^{1}$ en latere kerklike situasies in die vroeë stadium teruggeprojekteer het, kan nie met absolute sekerheid beweer word dat daaraan nie ' $n$ werklike historiese gebeure in die vroeë situasie ten grondslag lê nie. Deur redaksioneel ' $n$ nuwe vorm aan 'n bepaalde tradisie te gee, beteken nog nie dat so ' $n$ tradisie ongedaan gemaak kan word nie.

Die saak staan vanselfsprekend heel anders wanneer daar ' $n$ ander inligtingsbron oor dieselfde gebeure beskikbaar is, en veral as dit outentiek is soos in die geval van gegewens wat bekombaar is uit die briewe van Paulus. Sonder teëspraak word aanvaar dat Paulus se weergawe voorrang verleen moet word, al moet ook aanvaar word dat hy sy relaas vanuit sy eie oogpunt lewer. Dit is bekend dat ons in Galate 1 en 2 met die treffendste voorbeeld van onversoenbaarheid van Lukas- en Paulus-gegewens te make het. Dit lyk onvermydelik dat as daar gekorrigeer moet word, dit Handelinge is wat aan die hand van Paulus reggestel moet word en nie andersom nie.

Voordat oorhaastig gekorrigeer word, is dit egter raadsaam om eers seker te maak of daar werklik teenstrydighede is en of daar tog nie versoening moontlik is sonder om drasties die snoeiskèr in te lê nie. Is die verskille nie miskien van so 'n geringe aard dat dit nie wesenlik verander aan historiese gebeure en hulle betekenis nie?

Die bedoeling van hierdie ondersoek is nie om al die teenstrydighede of skynbare teenstrydighede wat deur Galate 1 en 2 na vore gebring word, te ondersoek of te probeer oplos nie. Ons wil ons slegs bepaal by die gebeure rondom en tydens die Apostelkonvent. Die probleme in verband met die twee berigte oor hierdie byeenkoms, is van sowel chronologiese as saaklike aard. Dit is bekend dat Lukas se weergawe van Paulus se eerste besoek aan Jerusalem, sy bewegings en optrede daar, radikaal verskil van Paulus se eie berig hieroor. Wat ons egter interesseer, is dat volgens Galate 2 (as dit na dieselfde geleentheid verwys) die Apostelkonvent plaasgevind het gedurende Paulus se tweede besoek aan Jerusalem, terwyl dit volgens Handelinge reeds sy derde besoek was. 
Ons kan die probleem met allerlei hipoteses probeer oplos, maar nie een bevredig werklik nie. Ons kan byvoorbeeld veronderstel dat Paulus die tweede besoek wat in Handelinge 11:29 vv vermeld word, verswyg omdat hy dit nie belangrik ag nie. Dit is egter moeilik te aanvaar in die lig van die feit dat Paulus aan die Galasiërs sy selfstandige optrede met betrekking tot die wetsvrye evangelieverkondiging wil beklemtoon, en wil aantoon watter verbintenisse hy wel met Jerusalem gehad het en wat die aard daarvan was. Hierby verseker hy die Galasiërs in 1:20 dat wat hy aan hulle skrywe, (voor God) die waarheid is en dus histories korrek weergegee word. 'n Ander moontlikheid is om te aanvaar dat Lukas se gegewens nie korrek is nie of dat hy van een besoek twee maak omdat hy sy inligting oor dieselfde besoek uit twee verskillende bronne gekry het. So is gepoog om die besoek van Handelinge 11:29 vv te koppel met dié van Handelinge $15^{2}$ of om dit te koppel met Galate 1:19 (volgens Paulus, sy eerste besoek) wat dan beteken dat die besoek van Handelinge 9:26 vv nie plaasgevind het nie. ${ }^{3}$ ' $n$ Ander oplossing wat aangebied is, is dat die besoek van Handelinge 9:29 vv gelyk te stel is met dié van Galate 2 op grond daarvan dat die besoek wat Paulus in Galate $1: 18$ vermeld, waarskynlik van so ' $n$ geheime aard was dat Lukas nie daarvan geweet het nie. ${ }^{4}$ Dit hou dan in dat die brief aan die Galasiërs heelwat vroeër as normaalweg (53-55 $\mathrm{nC}$ ) gedateer word, en dat die Apostelkonvent eers na die brief gevolg het en nie daarin vermeld kon word nie. Nog 'n gedagte is dat die besoek van Handelinge 11:29 vv gelykgestel moet word met Galate 2, wat eweneens beteken dat die konvent moes plaasgevind het nadat die brief aan die Galasiërs geskryf is. ${ }^{5}$ As argument ter ondersteuning hiervan word dan ook aangevoer dat Paulus as hy van die apostel-dekreet bewus was, dit in sy brief sou vermeld het om sy standpunt te verdedig. ${ }^{6}$ Hierby kan nog gevoeg word 'n opvatting soos dié van G Strecker. ${ }^{7} \mathrm{Hy}$ is van mening dat Lukas wel daarvan verneem het dat Paulus onder die heiden-gemeentes ' $n$ hulpfonds vir die gelowiges in Jerusalem ingesamel het, soos Paulus dit self in sy briewe vermeld (Gal 2:10; I Kor 16:1 vv; Il Kor 8:1 vv; Rom 15:25 vv). Op grond hiervan het Lukas die hulpfonds-besoek van Handelinge 11:29 vv gekonstrueer in aansluiting by die oorlewering oor die Agabus-profesie (Hand 11:28) en die besoek wat Paulus en Barnabas met die oog op die konvent aan Jerusalem gebring het. "Das Ergebnis liegt auf der Hand: Die sogenannte Zweite Reise des Paulus nach Jerusalem - entsprechend der Darstellung Act 11:27 ff - hat nicht stattgefunden; sie ist vielmehr als lukanische Kombination aus dem Zusammenschlusz verschiedener Traditions-elemente zu verstehen". ${ }^{8}$

Indien ons sou aanvaar dat Lukas en Paulus albei streng chronologies van die besoeke van Paulus aan Jerusalem berig gee, dan volg hieruit dat die besoek wat Paulus in Galate 2 vermeld, nie gelyk te 
stel is met die Apostelkonvent van Handelinge 15 nie. Maar nou stem die meeste navorsers juis daaroor saam dat die gebeure waarvan Paulus in Galate 2:1-10 melding maak, na dieselfde geleentheid verwys as dié wat Handelinge 15 beskrywe. Soos Strecker dit stel: "Die Identifizierung der Reise von Act 15 met der von Gal. 2:1 ff. ist denn auch eines der gesicherten Ergebnisse der Acta-Kritik. ${ }^{\prime 9}$ Hierdie bevinding is daarop gebasseer dat ondanks verskille, daar tog soveel ooreenkomste is tussen die gebeure wat in die twee onderskeie gedeeltes beskrywe word, dat daar geen twyfel kan wees dat albei oor die Apostelkonvent handel nie.

As ooreenkomste tussen die twee berigte sou op die volgende gewys kon word. In albei word Barnabas as reisgenoot van Paulus vermeld (Gal 2:1/Hand 15:2); albei maak ook melding van Judaïste met wie Paulus in stryd was oor die besnydenis (Gal 2:4/Hand 15:1, $2: 5,7: 24)$; volgens albei is daar tot' $n$ ooreenkoms geraak wat, hoewel die weergawe daarvan verskil, minstens daarop neerkom dat gelowiges uit die heidendom nie verplig sou word om hulle te laat besny nie. In albei word Petrus en Jakobus as leidinggewende figure genoem, hoewel dit opvallend is dat Paulus ook nog Johannes as een van die stuloi noem terwyl hy in Handelinge nie vermeld word nie.

Daar is egter ook opvallende verskille. Paulus vermeld nie Antiogië as punt van vertrek nie. Benewens Barnabas, vermeld hy ook Titus as ' $n$ reisgenoot. Anders as Handelinge is daar by Paulus nie daarvan sprake dat hy en Barnabas deur' $n$ gemeente afgevaardig is nie. Hy meld dat hy op grond van 'n openbaring of aanwysing (kata apokalupsin) na Jerusalem toe gegaan het. In aansluiting hierby lyk dit of die aanleiding vir sy besoek ook nie presies ooreenstem met dié van Handelinge nie. Volgens Handelinge het daar vanaf Judea sekere mense (tines) na Antiogië toe gegaan en geëis dat almal wat uit die heidendom tot die geloof kom, besny moes word (15:1). Dit lei tot 'n stryd met Paulus en Barnabas en die besluit van die gemeente om hulle na Jerusalem af te vaardig $(15: 2,3)$. Ook in Jerusalem volg ' $n$ hewige woordestryd met gelowiges uit die party van die Fariseërs, waarop besluit word om oor die saak te vergader $(15: 5,6)$. Daarenteen stel Paulus dat hy Jerusalem toe gegaar het om die evangelie wat hy verkondig, aan die gemeente daar voor te lê. Paulus gee nêrens die indruk dat hy van die Jerusalemse gemeente toestemming moes kry om met sy evangelieverkondiging voort te gaan nie. Ook gee hy nie die indruk dat as daar nie instemming sou wees nie, hy die inhoud van sy verkondiging sou verander nie. ${ }^{10} \mathrm{Hy}$ gaan as gelyke en selfstandige evangelieverkondiger na Jerusalem. Hy meld ook nie dat' $n$ voorafgaande stryd oor die besnydenis hom tot die besoek gedwing het nie. Dit is verder opvallend hoe passief Paulus en Barnabas volgens Handelinge 15 gedurende die beraad was, terwyl Galate 2 'n heel ander indruk laat. 
Daar is ook'n opmerklike verskil wat die besluit betref waartoe die byeenkoms geraak het. Paulus verklaar nie alleen dat geen druk op hom uitgeoefen is om Titus te laat besny nie, maar ook dat niks anders hom opgelê is (emoi gar hoi dokountes ouden prosanethento) of tot sy evangelie toegevoeg is nie(Galate $2: 6$ ). Verder verklaar hy met nadruk dat erken is dat die evangelieverkondiging aan die heidene aan hom toevertrou is, en dat die resultaat van die byeenkoms was dat hy en Barnabas as gelyke medewerkers aanvaar is en ooreengekom is dat hulle na die heidene sou gaan en die ander (stuloi) na die Jode (Galate 2:9). Geen melding word gemaak van die aposteldekreet wat in Handelinge 15 twee keer aan die orde kom $(15: 20,29)$ en in 21:25 nogeens vermeld word nie. Waarom vermeld Paulus dit nie terwyl dit so 'n prominente deel uitmaak van die besluit van die konvent? Het Paulus nie van so 'n dekreet geweet nie of het hy daarvan geweet maar wou dit nie vermeld nie? Volgens Handelinge is die besluit van die konvent aan die heiden-Christene in Antiogië, Sirië en Silisië gestuur. Die bedoeling kon egter nie wees dat die bepalinge daarvan net vir hierdie gebiede gegeld het nie. Daar is egter by Paulus geen aanduiding dat hy die bepalinge van die dekreet aan sy gemeentes voorgehou het nie. (vgl Handelinge 16:4). In I Korinte 8-10 waar hy oor die probleem van hoerery en die eet van afgodsoffervleis handel, skemer niks deur dat die dekreet aan die Korintiërs bekend was nie. Paulus verbied hier nie die eet van afgodsoffervleis nie maar raai dit slegs af wanneer dit 'n probleem sou skep vir iemand wat swak is in die geloof. ${ }^{11}$

Die bepalinge van die dekreet het in hoofsaak duidelik 'n rituele strekking. Die bedoeling hiervan was klaarblyklik dat dit die verkeer tussen Jood- en heiden-Christen moontlik moes maak en veral gemeenskaplike maaltye. As dit die bedoeling was, het Petrus dit reg verstaan deurdat hy daarna in Antiogië vryelik saam met heidenChristene geëet het. Die saak word egter onverklaarbaar wanneer gesante van dieselfde Jakobus wat vir die dekreet verantwoordelik was, Antiogië besoek, en Petrus en Barnabas uit vrees vir hulle die omgang met heiden-Christene staak. Die onversoenbaarheid van hierdie gebeure met die apostel-dekreet is wesenlik, tensy ons soos Stählin aanvaar dat hierdie optrede van Petrus nie ná nie maar vóór die konvent plaasgevind het. ${ }^{12}$

Hoewel die besluit van die konvent daarop neerkom dat besnydenis nie van heiden-Christene vereis sou word nie, kon die bepalinge van die dekreet, behalwe dié oor hoerery of bloedskande, nie vir Paulus 'n oorwinning gewees het nie. Dit het juis, wat die diëet betref, beperkinge op gelowiges geplaas, en Paulus het sulke beperkinge verwerp (I Kor 8:8; 10:25; Kol 2:20-23). ${ }^{13}$ Kan dit wees dat Paulus met sy beklemtoning dat niks hom opgelê is nie (Galate 2:6), teen 
die dekreet polemiseer as iets wat nie die besluit van die konvent was nie maar wel later vereis is?

Al hierdie bedenkinge teen die dekreet en Paulus se uitdruklike ontkenning dat iets hom opgelê is, lei tot die bykans algemeen aanvaarde oortuiging dat die dekreet nie deel uitgemak het van die besluit van die konvent nie maar eers later en waarskynlik heelwat later ontstaan het. Lukas moes dit geken het en het dit as afsluiting en besluit van die konvent hier ingevoeg. ${ }^{14}$ Die bepalings van die dekreet was buitendien ook niks nuuts nie. Reeds in Levitikus 17 en 18 is dit, benewens vir die Jode, ook vereis vir die nie-Jode wat onder hulle woonagtig was.

Ten slotte vermeld die Handelinge-berig ook niks van die versoek dat Paulus hom moes beywer vir die voorsiening van stoflike middele aan die gemeente van Jerusalem nie. Dit wil voorkom asof Paulus te kenne wil gee dat dit ' $n$ belangrike besluit en versoek van die byeenkoms was. Daarom het hy hom ook deurgaans daarvoor beywer.

Tot dusver het ons nog nie geantwoord op die vraag of Galate 2 en Handelinge 15 dieselfde geleentheid in gedagte het nie. Laat die verskille wat daar tussen die twee berigte bestaan, wel 'n identifikasie toe? Die feit dat die verloop van die byeenkoms en die resultaat daarvan verskillend weergegee word, hoef nog nie te beteken dat dit nie dieselfde geleentheid is wat ter sprake is nie. Soos reeds aangetoon, het die verskuiwing van die konvent van Handelinge 15 tot ná die geleentheid wat in Galate 2 beskryf word, implikasies vir die datering van Galasiërs. Dit sou ook teweeg bring dat 'n herrangskikking van die Pauliniese chronologie gedoen sal moet word. Dit sou verder die vraag laat ontstaan waarom Paulus dan nie in sy latere briewe selfs in die verbygaan van die Apostelkonvent melding gemaak het nie. Die ooreenkomste wat daar aan te merk is, al is hulle ook nie almal klinkklaar nie, dui tog daarop dat met' $n$ mate van reg aanvaar kan word dat albei berigte na dieselfde geleentheid verwys.

Maar hoe verklaar ons dan die verskille? Wat die getal besoeke betref, lyk die aanneemlikste verklaring dié te wees dat Lukas se inligting nie korrek was nie of dat hy sekere tradisies met mekaar verwar het en so van een besoek meer as een gemaak het. Die diepgaande verskille wat daar tussen Paulus en Lukas oor die eerste besoek bestaan, is al genoeg om 'n mens tot die oortuiging te bring dat Lukas van tweedehandse bronne afhanklik was wat die Jerusalem-besoeke van Paulus betref.

Sovêr dit die verloop en besluit van die konvent betref, is dit minder maklik om die verskille te verklaar. Wat egter toegegee moet word, is dat albei die berigte tendensieus van aard is en met ' $n$ bepaalde motief geskryf is. ${ }^{15}$ Paulus polemiseer teen die Judaïste in $\mathrm{Ga}$ lasië en verdedig die wetsvrye evangelie wat hy verkondig. Terself- 
dertyd wil hy die selfstandigheid en onafhanklikheid van sy apostoliese roeping en opdrag bo alle twyfel stel. Hy het sy opdrag nie van mense ontvang nie en ook nie die evangelie soos hy dit verkondig nie. Hy is ook nie aan Jerusalem of die leiersfigure aldaar verantwoording verskuldig nie. Hy het na Jerusalem toe gegaan om sy evangelie voor te lê, maar nie só dat afkeuring daarvan hom 'n tree van koers sou laat afwyk nie. "Doch enthält dieser Satz (Gal 2:2) sicher nicht die etwa zugestandene Bereitschaft, gegebenenfalls auf den Einspruch der Autoritäten hin seine von Gott und nicht von Menschen empfangene Botschaft überhaupt aufzugeben oder auch nur ihrem Wunsche gemäss abzuändern." ${ }^{16}$ In Jerusalem staan hy onwrikbaar vir die wetsvrye evangelie en dwing erkenning af, nie alleen vir die evangelie soos hy dit verkondig nie maar ook vir sy apostoliese gesag. Die resultaat is dat hy as medewerker in die evangelie en apostel vir die heidene erken word, en die eenheid van die kerk so gehandhaaf word. Hy was egter nie bereid dat sy evangelie ter wille van eenheid opgeoffer moes word nie. So verhoed hy dat die kerk 'n Joodse sekte word.

By Lukas lê die saak anders. Hy skryf met bepaalde ekklesiologiese interesse. Hy sien Jerusalem as die sentrum vanwaar die evangelie uitkring (vgl reeds Hand 1:8). Tot op hierdie stadium is die apostoliese of ampsgesag ook nog vir hom in Jerusalem gesetel. So was die werk wat Filippus in Samaria gedoen het, nie volledig en afgerond voordat Petrus en Johannes nie gestuur is om die gelowiges daar deur handoplegging die Heilige Gees te laat ontvang nie. (Hand 8:4 vv). Nadat heidene in Antiogië deur die evangelieverkondiging van mense uit Siprus en Sirene gelowig geword het, is Barnabas deur die gemeente in Jerusalem daarheen gestuur (Hand 11:20 vv). Dit is dan ook hy wat Paulus in Tarsus gaan haal en hom so met sy eintlike werk vir die evangelie laat begin. Wanneer daar dan 'n tweestryd in Antiogië oor die besnydenis ontstaan, word afgevaardigdes na Jerusalem gestuur. In Jerusalem is dit die apostoloi en presbuteroi wat oor die saak byeenkom en gedurende die vergadering is dit Petrus en Jakobus wat elk met ' $n$ indrukwekkende rede die toneel oorheers. Paulus vervul in die verloop van die konvent maar ' $n$ ondergeskikte rol en hy en Barnabas rapporteer slegs wat God deur hulle onder die heidene gedoen het. Die besluit van die vergadering word ook nie deur Paulus en Barnabas na Antiogië oorgebring nie maar deur Judas en Silas wat deur die vergadering daarvoor afgevaardig word. ${ }^{17}$

Is dit nou vir ons moontlik om die twee berigte so met mekaar te harmoniseer dat ons daaruit 'n rekonstruksie van die Apostelkonvent sou kon maak? Sou ons dus tog met sekerheid kon uitmaak wat histories werklik die aanleiding, die verloop en resultaat van die byeenkoms was? Sou ons Handelinge en Galasiërs as bronne van gelyke historiese waarde kon gebruik as die tendensieuse daarin buite 
rekening gelaat word? Met so 'n onderneming duik weer die probleem op van gelyke of meerdere en mindere historiese betroubaarheid. Dideluis het in hierdie verband kategories verklaar: "Die Darstellung der Verhandlung bei Lukas ist nur literarisch-theologisch und kann auf geschichtlichen Wert keinen Anspruch machen". ${ }^{18}$ Hierby sluit Bornkamm aan wanneer hy sê: "Einen eigenen Quellenwert besitzt der Actabericht jedoch nicht,"19 en 'n bietjie verder: "Dennoch kann kein Zweifel sein, dass wir in Gal 2 einen authentischen Bericht über den Konvent, ja sogar die einzige historisch brauchbare Quelle vor uns haben. ${ }^{\prime 20}$

Aan hierdie uitsprake lê ten grondslag dat Lukas wat sy weergawe van die verloop van die konvent betref, sterk redaksioneel te werk gegaan het. ${ }^{21} \mathrm{Hy}$ het wel geweet van 'n konflik wat in Antiogië oor die besnydenis ontstaan het en tot in Jerusalem weerklank gevind het. Oor wat werklik in Jerusalem gebeur het, het hy egter niks oorgelewer nie. ${ }^{22}$ Die toesprake van Petrus en Jakobus is sy eie komposisie, en volgens Dibelius wel vir die leser verstaanbaar maar nie vir die deelnemers aan die konvent nie. ${ }^{23}$ Hiermee wil hy met teologiese en ekklesiologiese interesse die kontinuiteit in die verloop van die heilsverkondiging skilder en aantoon dat die heidensending nie mensewerk is nie en nie volgens die beslissing van mense geskied nie maar in opdrag van God. Hy laat ook duidelik na vore kom dat Petrus die eerste was om in opdrag van God die evangelie aan die heidene te verkondig. Hierdeur word die begin van die heidensending gekoppel aan die apostelkring en so ook aan Jerusalem, terwyl Paulus dit só verstaan dat nie Petrus nie maar hý deur God tot heidensending geroep is. (Gal 2:7-9). Dat Paulus apostel vir die heidene is, ontken Lukas nèrens nie, maar vir hom is dit belangrik dat God die deur vir die heidensending vanuit Jerusalem oopgemaak het en dit deur een van die twaalftal, wat tot op hierdie stadium in die verloop van die kerkvorming in die middelpunt gestaan het. Hierdeur word duidelik getoon dat daar kontinuïteit in die uitbreiding van die evangelie was. Die feit van die heidensending het nie van buite gekom en vanuit 'n ander kring begin nie. In lyn hiermee word ook wat die verloop van die konvent betref, die inisiatief van Paulus af verskuif na Petrus en Jakobus. Tot op hierdie stadium het hulle die leiding in die kerk geneem en so ook op die konvent. Saam met die presbuteroi plaas hulle finaal die seël van goedkeuring op die heidensending en word dit deur hulle amptelik gelegitimeer. Dit is deur hulle inisiatief en voorspraak dat die deur tot lidmaatskap van die Godsvolk vir die heidene geopen word. Deur hulle toedoen word 'n breuk in die geledere van die kerk voorkom en die eenheid bewaar. So vorm die Apostelkonvent die middelstuk van die boek Handelinge. Hiermee word die belangrike voorstadium van fondamentlegging en vestiging van die kerk afgesluit, en van hieraf aan word die 
perspektief wyer en kan die kerk as universele kerk tot volle ontplooiing kom.

As ons nou die dekreet vir'n oomblik buite rekening laat en vra na die sentrale betekenis van die resultaat wat volgens die twee berigte onderskeidelik bereik is, dan skyn daar nie 'n wesenlike verskil te wees nie. Albei wil tog seker sê dat daar erkenning verleen is aan die wetsvrye evangelie soos Paulus dit verkondig het en dat hierdie evangelie voortgang onder die heidene moes hê. Om dit moontlik te maak en om vir die heidene geen struikelblok in die weg te lê nie, berig albei dat die nakoming van die Mosaiëse wet nie van die heidene vereis sou word nie.

Teenoor Lukas moet die Pauliniese berig as die historiesbetroubare aanvaar word. Die feit dat daar wel verskille in die onderskeie weergawes van dieselfde gebeurtenis bestaan, hoef nie afbreuk te doen aan die belangrikheid van hierdie byeenkoms in die vroeë geskiedenis van die kerk nie. Al was dit ook so dat daar hierna in baie Pauliniese gemeentes, soos in die gemeentes van Galasië steeds heftige teenk.inting van die kant van die Judaïste gekom het, was die saak minstens "amptelik" uitgemaak. Paulus kon hom hierop eerstehands bervep en dit word in wese bevestig deur die tradisie wat die outeur van Handelinge tot sy beskikking gehad het.

W'at die apostel-dekreet betref, is dit bekend dat daar aansienlike rariasies te bespeur is tussen die Aleksandrynse-, en Westerse- en Se-areaanse teksfamilies. ${ }^{24}$ Dit is duidelik dat die variasies te wyte is din die vraag of die dekreet suiwer ritueel of uitsluitlik moreel-sedelik geinterpreteer moet word, of iets van albei bevat. 'n Bevredigende antwoord op hierdie vraag en die oplossing van die tekskritiese probleem sou egter nog nie kon uitmaak of die dekreet wel ill-turies by die konvent tuishoort en die besluit van die konvent was inc

Ons het reeds daarop gewys dat die bepalings van die dekreet nie vir mense uit die Joodse gemeenskap nuut was nie, dat dit eienaardig is dat Paulus in sy briewe niks daarvan vermeld waar die geleentheid hom voordoen nie, en dat Petrus se optrede in Antiogië ná die konvent volkome onverklaarbaar bly as die dekreet werklik deel van die besluit was. ${ }^{25}$ Hierby lyk dit asof Lukas homself in Handelinge 21:25 weerspreek. Hier laat hy Jakobus en die ouderlinge vir Paulus sê peri de ton pepisteukoton ethnon hemeis epesteilamen ... Dit lyk dus asof Paulus hier by sy laaste besoek aan Jerusalem vir die eerste keer van die apostel-dekreet en sy inhoud kennis neem. ${ }^{26}$

Indien dit so is dat die dekreet nie histories by die konvent tuishoort nie, hoe moet ons ons dan die opname daarvan in die Handelinge tradisie voorstel? In die eerste plek sou nie fout gevind kon word met die gedagte dat die bepalings van die dekreet van toepassing moes gewees het in 'n gemeente of gemeentes met sowel Joodse 
as nie-Joodse lidmaatskap nie. Alleen in so 'n gemeente sou die nakoming van die rituele bepalings van Joodse kant gesien, van die nie-Jode vereis moes word om gemeenskaplike verkeer moontlik te maak. Tot op hierdie stadium was die bepalings 'n vanselfsprekende vereiste wat die Jodendom met betrekking tot nie-Jode in hulle midde gestel het. In kringe waar gelowiges uit die Jodendom nog sterk in die Mosaiëse tradisie bly voortleef het, moes hierdie bepalings as ' $n$ vanselfsprekendheid in die Christendom in verleng gewees het. Hoewel Paulus wat homself betref, seker nie radikaal met alle Joodse tradisies gebreek het nie, is dit onwaarskynlik dat hy hom met hierdie rituele bepalings sou vereenselwig of dat hy mede-verantwoordelik daarvoor sou wees (vgl Kol 2:21). Terwyl Paulus in Romeine $14: 13 \mathrm{vv}$ en I Korinte 8 waarsku dat iemand wat swak is in die geloof nie tot struikeling gebring moet word deur wat' $n$ mens eet of drink nie, sê hy in dieselfde asem dat dit in die koninkryk van God nie gaan om wat ' $n$ mens eet of drink nie (Romeine 14:17) en raai hy sy lesers aan om enigiets te eet wat in die slaghuis te koop aangebied word sonder om navraag te doen (I Korinte 10:25), en ook om sonder navraag te eet wat aan jou voorgesit word (I Korinte 10:27). Hoewel Paulus dus duidelik stel dat die medegelowige in aanmerking geneem moet word wanneer iets vir hom aanstootlik is, lê hy nie rituele voorskrifte neer nie en verwys hy nie na sodanige neergelegde voorskrifte nie.

Lukas moes wel daarvan bewus gewees het dat die bepalings van die dekreet in sulke kringe gegeld het. Om ter wille van die Joodse gelowiges "amptelike" gesag aan hierdie maatreëls te verleen, plaas hy die dekreet in die konteks van die Apostelkonvent aangesien daar geen beter kontekstuele verband daarvoor gekies kon word nie as juis die Apostelkonvent. ${ }^{27}$

Hierdie poging tot die oplossing van die onderhawige probleem word aangebied met die hoop dat dit verdere navorsing met betrekking tot hierdie saak sal stimuleer. Tegelyk word dit aangebied as betuiging van groot waardering en agting vir 'n kollega en vriend wat deur sy eie wetenskaplike werk, meesterskap van sy vak en nugtere denke, altyd die grootste bewondering afgedwing het, prof F J van Zyl, by die aanvaarding van sy emeritaat. Mag die jare vorentoe vir gesin, kerk en volk steeds van groot betekenis wees.

1. Vgl bv M Dibelius, Aufsätze zur Apostelgeschichte, Göttingen 3 1957, veral bl 120-162.

2. So bv J Jeremias, Untersuchungen zum Quellenproblem d'r Apostelgeschichte, ZNW 36 (1937), 218; E Haenchen, Die Apostelge'schichte, Göttingen 11 1957, 386; H Conzelmann, Die Apostelgeschichte, Tübingen 1963, 69; A Oepke, Der Brief des Paulus an die Galater, Berlyn sj (1964), 52; H Conzelmann, Geschichte des Urchristentums, Göttingen 1971, $67 \mathrm{vv}$. 
3. So P Parker, Once more, Acts and Galatians, Joum Bib Lit 86 (2:67), 175-182.

4. So D R de Lacey, Paul in Jerusalem, NTS 20 (1, 73), 82-86.

5. Kyk vir hierdie standpunt oa $W$ Ramsay, St Paul the Traveller and Roman Citizen, London 1905; F F Bruce, The Acts of the Apostels, London ${ }^{2} 1956,38 \mathrm{vv}$; C S C Williams, The Acts of the Apostles, London ${ }^{2} 1971,30$ hoewel minder seker.

6. F F Bruce, aw, 38 .

7. G Strecker, Die sogenannte zweite Jerusalemreise des Paulus, ZNW 53 (1-2, '62), 67-77.

8. G Strecker, aw, 75.

9. G Strecker, aw, 74 .

10. Vgl G Bornkamm, Paulus, Stuttgart, sj (1970), $57 \mathrm{vv.}$

11. Vgl H Conzelmann, Apostelgeschichte, 85; A Oepke, aw, 53; G Bornkamm, aw, 63.

12. Kyk G Stăhlin, Die Apostelgeschichte, Göttingen 1975, 209 vv. Hy is van mening dat Paulus ten opsigte van hierdie gebeurtenis nie streng chronologies dink nie. Volgens hom is die historiese gedeelte van Galasiërs wat met 1:13 begin, by 2:10 afgesluit sodat van 2:11 af nie 'n gebeurtenis ná die konvent beskryf word nie, maar voorafgaande daaraan. Hy beskou so 'n gebeurtenis juis ná die konvent as onmoontlik. Kan onş dit egter uit 2:11 vv aflei. Dit lyk onwaarskynlik.

13. Vgl P Parker, aw, 177.

14. Kyk E Haenchen, aw, 415 vv; M Dibelius, aw, 88 vv; H Conzelmann, Geschichte, 72 vvl F Mussner, Der Galaterbrief, Freiburg 1974, 130; G Bornkamm, aw. 63; E Lohse, Grundriss der neutestamentlichen Theologie, Stuttgart sj (1974) 72; O Collmann, Petrus, Jünger, Apostel, Märtyrer, Zürich 1952, 49.

15. Vgl F Mussner, aw, 131; G Bornkamm, aw, 52 vv.

16. Vgl G Bornkamm, aw, 54 .

17. Die rede hiervoor kan natuurlik ook wees dat voorkom moes word dat Paulus en Barnabas daarvan verdink kon word dat hulle hulle eie interpretasie van die besluite aan die gemeente in Antiogië oordra.

18. M Dibelius, aw, 90 ; so ook E Haenchen, aw, 410.

19. G Bornkamm, aw, 53 .

20. Ibid. En op ' $n$ ander plek beweer hy (aw 62): “Der Bericht der Apostelgeschichte lässt von alledem, was wir dem Galaterbrief entnommen haben, nichts mehr erkennen ..."

21. Vgl ook E Haenchen, aw, 407.

22. M Dibelius, $a w, 88$.

23. Ibid.

24. Kyk hiervoor B M Metzger, A textual commentary on the Greek New Testament (United Bible Societies), London 1971, 429 vv.

25. Vgl E Haenchen, aw, 418 wat juis op grond van hierdie gebeurtenis nie kan aanvaar dat Jakobus die outeur van die dekreet kon wees nie.

26. Vir die opvatting dat hierdie woord nie tot Paulus gerig is nie, maar dat die dekreet redaksioneel vir die inligting van die leser herhaal word vgl E Haenchen, aw, 417, H Conzelmann, aw, 123.

27. So tereg C S C Williams, aw, 184. 